\title{
Uso da Zootecnia de Precisão na Avaliação do Comportamento de Leitões Lactentes Submetidos a Diferentes Sistemas de Aquecimento ${ }^{1}$
}

\author{
Iran José Oliveira da Silva ${ }^{2}$, Héliton Pandorfi ${ }^{3}$, Sônia Maria Stefano Piedade 4
}

RESUMO - Objetivou-se, nesta pesquisa, avaliar o comportamento de leitões em diferentes sistemas de aquecimento, por meio de análise de imagem e identificação eletrônica, na sala da maternidade, com 80 animais entre o nascimento e o desmame. Os tratamentos adotados para avaliação da eficiência dos diferentes sistemas de aquecimento foram: piso térmico, lâmpada incandescente, resistência elétrica e lâmpada de infravermelho. O delineamento experimental foi em blocos casualizados com quatro tratamentos e 18 blocos, as médias foram comparadas pelo teste Tukey. A avaliação física dos ambientes foi realizada por intermédio da temperatura de bulbo seco (Ts), temperatura de bulbo úmido (Tu) e temperatura de globo negro (Tg), registradas por cabos termopares tipo T armazenados em uma plataforma automática de dados, em intervalo horário. Índice de temperatura de globo e umidade (ITGU), carga térmica radiante (CTR) e entalpia $(\mathrm{H})$ foram calculados usando as variáveis ambientais registradas. Os dados ambientais foram registrados em ambiente externo, na sala da maternidade e no interior de cada abrigo escamoteador, durante 18 dias. Ganho de peso diário (GPD) e mortalidade também foram registrados. A avaliação comportamental foi realizada utilizando a análise de imagem, identificação eletrônica. Para o período de inverno, o uso de lâmpada incandescente e resistência elétrica foi mais adequado sob o ponto de vista térmico, durante a primeira e segunda semanas, entretanto, considerando-se o reflexo do aquecimento no comportamento dos leitões na terceira semana, o piso térmico foi o que proporcionou melhor condição de conforto aos animais.

Palavras-chave: análise de imagem, bem-estar animal, conforto térmico, suinocultura

\section{Use of Animal Precision Production in the Behavior Evaluation of Lactation Piglets Submitted to Different Heating Systems}

\begin{abstract}
The objective of this research was to evaluate the behavior of piglets at different heating systems using the image analysis and electronic identification devices. This research was developed in the farrowing house, with 80 piglets from birth to weaning. The treatments were the different heating systems: heat mat, standard heat lamp, electric resistance and infrared lamp. A completely randomized block design with four treatments and 18 blocks was used. Environmental dry bulb temperature (Td), wet bulb temperature (Tw) and black globe temperature (Tg) were measured with T thermocouples and recorded each 60 minutes in a dataloger. The thermal comfort indexes: black globe humidity index (ITGU), radiant thermal load (CTR) and enthalpy (H) were calculated using the recorded climatic variables. The climatic data was taken inside and outside the farrowing house and inside each studied creep, 18 days long. Daily weight gain (GPD) and mortality were also recorded. A Tukey test with $1 \%$ of probability was performed to compare the results averages. The behavior of the piglets was evaluated using the image analysis, electronic identification. The results indicated for winter time the use of the standard heat lamp and electric resistance were recommended under the thermal point of view, for first and second week, however, considering the reflex of the heating in the behavior of the piglets in the third week, the heat mat was what provided better comfort condition to the animals.
\end{abstract}

Key Words: image analysis comfort, animal welfare, thermal comfort, swine production

\section{Introdução}

A suinocultura é uma atividade que exige muita dedicação do criador para alcançar bons índices de produtividade e, em conseqüência, resultados econômicos satisfatórios. Fatores ambientais externos e o microclima dentro das instalações exercem efeitos diretos e indiretos sobre a produção de suínos, acarretando a redução da produtividade, com conseqüentes prejuízos econômicos à exploração.

Na suinocultura, um dos maiores problemas relacionados ao conforto térmico e bem-estar animal está na maternidade, onde se têm dois ambientes distintos a serem avaliados, com exigências bem diferenciadas.

${ }^{1}$ Projeto financiado pela FAPESP.

2 Eng. Agrícola, Prof. Doutor, Departamento de Engenharia Rural. NUPEA/ESALQ-USP. Av. Pádua Dias, 11. Cx. 09. Piracicaba, SP. CEP: 13418-000. Tel. (019)3429.4217 r. 238. E.mail: ijosilva@esalq.usp.br

${ }^{3}$ Eng. Agrônomo, Doutorando do curso de Física do Ambiente Agrícola - NUPEA/ESALQ-USP.

${ }^{4}$ Eng. Agrônomo, Profa. Doutora, Departamento de Ciências Exatas ESALQ/USP. 
Na realidade, essa situação é um dos grandes problemas do produtor, pois, em um pequeno espaço físico, há a necessidade de proporcionar dois microambientes diferentes e, caso isso não ocorra, o desempenho tanto das matrizes quanto dos leitões não será satisfatório.

Os suínos, por suas características fisiológicas, possuem dificuldades em adaptação às flutuações térmicas ambientais. A faixa de temperatura para seu conforto varia com a idade. Para o leitão, ao nascimento, a faixa de conforto está entre 32 e $34^{\circ} \mathrm{C}$ e aos 35 dias, entre 29 e $31^{\circ} \mathrm{C}$, sendo que a temperatura ideal para a matriz está entre 16 e $21^{\circ} \mathrm{C}$ (Perdomo et al., 1987).

O leitão recém-nascido possui os sistemas de termorregulação e imunitário pouco desenvolvidos, tornando-o sensível a baixas temperaturas ambientais. Nessas condições, o leitão reduz sua atividade motora e, conseqüentemente, a ingestão de colostro, acarretando maior incidência de doenças, maior número de leitões esmagados e alta taxa de refugos na desmama, sendo necessários alguns cuidados especiais. A regra básica é fornecer aos leitões um ambiente limpo, desinfetado, seco e aquecido. Isso significa investir em piso adequado e sistemas de aquecimento (Perdomo et al., 1987).

Um campo extenso a ser pesquisado e discutido é o do comportamento animal, como indicador de bem-estar em um sistema de produção. A avaliação e os controles interativos do conforto térmico dos suínos pela análise de imagem superam os problemas inerentes ao método convencional, pois utiliza-se o próprio animal como um biosensor em resposta aos reflexos do ambiente por meio da análise comportamental (Xin \& Shao, 2002).

Objetivou-se, com esta pesquisa, avaliar os diferentes sistemas de aquecimento em abrigos escamoteadores para leitões, utilizando como ferramenta de avaliação a identificação eletrônica e a análise de imagem para o entendimento do comportamento animal.

\section{Material e Métodos}

A pesquisa foi realizada na granja Querência, propriedade cuja principal atividade é a produção industrial de suínos, localizada no município de Elias Fausto, SP, apresentando latitude de $22^{\circ} 02^{\prime}$ S, longitude de $47^{\circ} 22^{\prime} \mathrm{W}$ e altitude de $580 \mathrm{~m}$, o clima da região é caracterizado como mesotérmico Cwa (tropical de altitude), com temperatura do mês mais frio entre -3 e $18^{\circ} \mathrm{C}$, inverno seco e temperatura do mês mais quente maior que $22^{\circ} \mathrm{C}$, segundo classificação Köppen (Pereira et al., 2002).

O desenvolvimento da pesquisa foi na sala da maternidade, no período compreendido entre o nascimento e o desmame dos leitões, com duração média de 18 dias, de acordo com o manejo adotado na granja. A fase experimental foi realizada no período de inverno (junho a agosto de 2002).

$\mathrm{Na}$ pesquisa, foi avaliada a eficiência de quatro sistemas de aquecimento nos abrigos escamoteadores, constituindo-se os seguintes tratamentos: tratamento 1 - Abrigo escamoteador equipado com piso térmico de placas pré-moldadas de compósitos biomassa vegetal-cimento, aquecido por meios de resistência elétrica, confeccionadas no Laboratório de Ensaios de Materiais, da Faculdade de Engenharia Agrícola da Unicamp, com dimensões de 0,40 x $0,50 \mathrm{~m}$, compondo um conjunto de 3 placas por abrigo $(378 \mathrm{~W})$, de acordo com Rossi, et al., (2002); tratamento 2 Abrigo escamoteador equipado com lâmpada incandescente de $200 \mathrm{~W}$, fixada na parede de uma das extremidades do abrigo, a uma altura de $0,50 \mathrm{~m}$ do piso; tratamento 3 - Abrigo escamoteador equipado com resistência elétrica de $200 \mathrm{~W}$, fixada na parede de uma das extremidades do abrigo, a uma altura de 0,50 $\mathrm{m}$ do piso; tratamento 4 - Abrigo escamoteador equipado com lâmpada de infravermelho de $250 \mathrm{~W}$, fixada na parede de uma das extremidades do abrigo, a uma altura de $0,50 \mathrm{~m}$ do piso.

Os abrigos escamoteadores $(1,50 \mathrm{~m} \times 0,55 \mathrm{~m} \mathrm{x}$ $0,65 \mathrm{~m} \mathrm{de}$ ) tinham área total de $0,82 \mathrm{~m}^{2}$, com volume de $0,53 \mathrm{~m}^{3}$. Toda área de piso foi coberta por uma cama de maravalhas, e os sistemas de aquecimento permaneceram acionados durante todo o período experimental.

A sala da maternidade é caracterizada tipologicamente por 23,0 $\mathrm{m}$ de comprimento por 13,5 $\mathrm{m}$ de largura e pé direito de $2,8 \mathrm{~m}$, forro revestido com placas de poliestireno, acompanhando a face inferior do telhado. Cobertura com telhas de cerâmica do tipo francesa, sendo que, ao longo da sala, a instalação apresenta oito janelas de cada lado, com peitoril de $1,50 \mathrm{~m}$, altura de $1,3 \mathrm{~m}$ e 2,59 $\mathrm{m}$ de largura, totalizando uma área de abertura de janelas de 53,95 $\mathrm{m}^{2}$.

As cortinas laterais permaneceram fechadas praticamente o tempo todo, sendo abertas somente nos horários mais quentes do dia, garantindo a renovação de ar no interior da instalação.

Foram alojadas na sala 34 matrizes, em 34 celas parideiras, e selecionadas oito matrizes aleatoria- 
mente e sua respectiva leitegada, duas por tratamento. As baias possuíam dimensões de $1,7 \mathrm{~m}$ de largura por $2,8 \mathrm{~m}$ de comprimento e $1,2 \mathrm{~m}$ de altura, totalizando $4,76 \mathrm{~m}^{2}$.

$\mathrm{O}$ estudo foi realizado com animais híbridos threecross (Landrace x Large White x Duroc). Os leitões que fizeram parte do estudo eram de matrizes de mesma ordem de parto, selecionadas com o objetivo de eliminar fatores de interferência, habilidade materna, número de leitões/leitegada. Foram selecionadas matrizes de $6^{\mathrm{a}}$ ordem, de acordo com a disponibilidade de animais, com previsão de parto que coincidia com o período experimental. Cada baia apresentou 10 leitões que, após os partos, foram remanejados por critério de peso e número de animais/leitegada de modo que todos os abrigos estudados permanecessem com um número fixo de 10 leitões.

Durante o período experimental, foram monitoradas as variáveis ambientais no abrigo escamoteador, na sala da maternidade e no ambiente externo. Foram registradas por meio de sensores conectados a uma plataforma automática de coleta de dados as seguintes variáveis: temperatura de bulbo seco (Ts), temperatura de bulbo úmido (Tu), temperatura de globo negro ( $\mathrm{Tg}$ ) e velocidade do vento (VV).

O registro dos dados de temperatura foi realizado em intervalos de 15 minutos, durante os 18 primeiros dias de vida dos leitões, período em que os animais permaneceram na maternidade. Os sensores para a obtenção da temperatura eram compostos por uma rede de cabos termopares do tipo T (cobre-constantan).

Nos abrigos escamoteadores, os sensores para determinação da Ts, Tu e Tg foram acoplados na tampa, distando $0,55 \mathrm{~m}$ do piso. Na sala da maternidade, as variáveis ambientais foram registradas no interior da instalação, na região central das baias estudadas, a uma altura de 1,3 $\mathrm{m}$ do piso. Na área externa às instalações, os sensores foram instalados no interior de um abrigo meteorológico, a 1,5 $\mathrm{m}$ de altura da superfície, representando o microclima do local.

Para determinação da eficiência térmica em cada tratamento, com os dados de temperatura dos ambientes estudados, foram determinados índice de temperatura de globo negro e umidade (ITGU), carga térmica radiante (CTR) e entalpia $(\mathrm{H})$ por meio das seguintes equações:

a) índice de temperatura de globo negro e umidade, proposta por Buffington et al. (1981):

$$
I T G U=T g+0,36 T p o-330,08
$$

em que: $T g$ é temperatura de globo negro (K) e Tpo, temperatura de ponto de orvalho $(\mathrm{K})$.

b) índice de carga térmica radiante $\left(\mathrm{W} \cdot \mathrm{m}^{-2}\right)$, proposta por Esmay (1982):

$$
\begin{gathered}
C T R=\tau(T M R)^{4} \\
T R M=100\left\{\left[2,51(V V)^{0,5}(T g-T s)+\left(\frac{T g}{100}\right)^{4}\right]^{0,25}\right\}
\end{gathered}
$$

em que TRM é temperatura média radiante; $V V$, velocidade do vento $\left(\mathrm{m} . \mathrm{s}^{-1}\right) ; T g$, temperatura de globo negro $(\mathrm{K})$; $T s$, temperatura de bulbo seco $(\mathrm{K})$; $t$, $5,67 * 10^{-8} \mathrm{~K}^{-4}$.W.m ${ }^{-2}$ (constante de Stefan-Boltzmann).

c) entalpia ( $\mathrm{kJ} / \mathrm{kg}$ ar seco), proposta por Albright (1990):

$$
H=1,006 T s+W(2501+1,805 T s)
$$

em que $T_{s}=$ temperatura de bulbo seco $\left({ }^{\circ} \mathrm{C}\right)$; $W=$ razão de mistura (kg vapor d'água/kg ar seco).

A análise dos parâmetros zootécnicos dos animais foi realizada adotando-se as metodologias convencionais para o registro de ganho de peso e mortalidade dos leitões na maternidade.

O ponto fundamental desta pesquisa é justamente a avaliação dos sistemas de aquecimento, usando a análise comportamental dos animais, para compreensão da eficiência do sistema em função da sensação do conforto animal.

Utilizou-se, como ferramentas para registro desses dados, microcâmeras preto e branco com lente de 2,45 mm e "leds" de infravermelho, o que permitiu obter as imagens nos abrigos onde não haviam fontes de luz, no caso dos abrigos equipados com piso térmico e resistência elétrica.

As imagens registradas foram analisadas com o objetivo de verificar a freqüência de acesso e o tempo de permanência dos animais no abrigo, permitindo a descrição do comportamento dos animais dentro do abrigo, em função dos sistemas de aquecimento e das variáveis ambientais envolvidas no estudo.

As imagens foram registradas diariamente em intervalos de 2 minutos, sendo gerenciadas pelo software videocap, armazenando as informações em um banco de dados para posterior análise. 
A análise das imagens foi feita para três dias críticos, considerados nessa pesquisa como os dias de menor entalpia do período, segundo Moura et al. (1997). Deve-se enfatizar que, por se tratar de aquecimento, adotou-se a menor entalpia como crítica, por considerar a menor quantidade de calor presente em uma parcela de ar seco.

Foi utilizado o delineamento em blocos casualizados (DBC), adotando-se quatro tratamentos e 18 blocos, considerando os blocos como os números de observações diárias estudadas no experimento. As médias das variáveis resposta dos microambientes foram comparadas pelo teste Tukey $(\mathrm{P}<0,01)$. Toda a análise estatística foi realizada por meio do programa estatístico Statistical Analysis System - SAS (SAS, 1992).

Foi realizada análise de regressão, para comparação entre as temperaturas na maternidade em função das temperaturas externas (abrigo meteorológico).

Para descrição do comportamento, freqüência de utilização dos locais monitorados, foi realizada uma análise de regressão entre o número de animais e a temperatura de bulbo seco na sala da maternidade.

\section{Resultados e Discussão}

A comparação entre tratamentos, apresentados na Tabela 1, é o resultado médio diário das variáveis resposta dos microambientes estudados, abrigos escamoteadores e seus respectivos sistemas de aquecimento. Verificou-se que todos os tratamentos apresentaram diferenças significativas para temperatura de bulbo seco (Ts), temperatura de globo negro ( $\mathrm{Tg}$ ) e umidade relativa (UR).

Observa-se, por meio de valores médios de Ts, que o ambiente com piso térmico apresentou menor temperatura no microclima gerado, seguido da lâmpada incandescente, resistência elétrica e lâmpada de infravermelho, respectivamente. De modo geral, pode-se inferir que, para zona de conforto térmico para os leitões na fase da maternidade, os três primeiros tratamentos são recomendados, porém, deve-se ressaltar que esses dados são valores médios diários.

A Figura 1 mostra a influência do efeito dos diferentes sistemas de aquecimento na temperatura interna dos abrigos escamoteadores. Nessas condições, verifica-se que o aquecimento proporcionado aos leitões, pela lâmpada incandescente e resistência elétrica, foi o que mais se aproximou da faixa de conforto térmico dos animais, 32 a $28^{\circ} \mathrm{C}$ (Silva, 1999). O tratamento, piso térmico esteve abaixo da condição
Tabela 1 - Valores médios das variáveis ambientais temperatura de bulbo seco (Ts), temperatura de globo negro ( $\mathrm{Tg}$ ) e umidade relativa (UR) observadas durante a permanência dos leitões na maternidade

Table 1 - Average values of the environment traits dry bulb temperature (Ts), black globe temperature ( $T g$ ) and relative humidity observed during the permanence of piglets in the farrowing house

\begin{tabular}{lccc}
\hline $\begin{array}{l}\text { Tratamentos } \\
\text { Treatments }\end{array}$ & $\operatorname{Ts}\left({ }^{\circ} \mathrm{C}\right)$ & $\operatorname{Tg}\left({ }^{\circ} \mathrm{C}\right)$ & $\mathrm{UR}(\%)$ \\
\hline $\begin{array}{l}\text { Piso térmico } \\
\text { Heat mat }\end{array}$ & $28,7 \mathrm{~d}$ & $28,9 \mathrm{c}$ & $60,5 \mathrm{a}$ \\
$\begin{array}{l}\text { Lâmpada incandescente } \\
\begin{array}{l}\text { Standard heat lamp } \\
\text { Resistência elétrica }\end{array}\end{array}$ & $32,2 \mathrm{c}$ & $32,8 \mathrm{~b}$ & $48,9 \mathrm{~b}$ \\
$\begin{array}{l}\text { Eletric resistence } \\
\text { Lâmpada de infravermelho }\end{array}$ & $32,9 \mathrm{~b}$ & $32,9 \mathrm{~b}$ & $50,6 \mathrm{c}$ \\
$\begin{array}{l}\text { Infrared lamp } \\
\text { Valoresmedioscom }\end{array}$ & $41,8 \mathrm{a}$ & $31,7 \mathrm{~d}$ \\
\hline
\end{tabular}

Valores médios com letras diferentes, na mesma coluna, diferem $(P<0,01)$ estatisticamente pelo pelo teste Tukey.

Average values with differents letters, in the same column, statistics differ $(P<.01)$ by Tukey test.

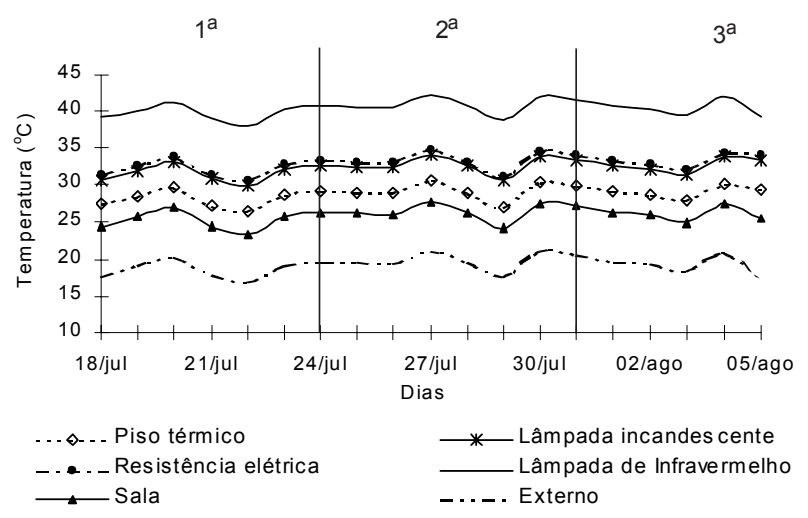

Figura 1 - Variação da temperatura média diária nos diferentes tratamentos na sala da maternidade e no abrigo meteorológico (ambiente externo).

Figure 1 - Variation of average daily temperature in the different treatments in the farrowing house and the meterological shelter (external environment).

recomendada, principalmente na $1^{\mathrm{a}}$ semana de vida dos animais. Esses resultados demonstram que a condição de conforto, na $1^{\mathrm{a}}$ e $2^{\mathrm{a}}$ semana de vida dos animais, foi atendida pelos tratamentos, lâmpada incandescente e resistência elétrica. Para o tratamento piso térmico, a disponibilidade de energia, proporcionada pela fonte de aquecimento, não foi suficiente para as duas semanas iniciais, atendendo as exigências dos animais apenas na $3^{\mathrm{a}}$ semana.

Com relação à lâmpada de infravermelho, os dados referentes à temperatura, no interior do abrigo, 
esteve, em média, sempre acima da condição ideal, durante toda fase experimental, ultrapassando o valor da temperatura crítica superior (TCS) de 38 a $33^{\circ} \mathrm{C}$ (Mount, 1968; Curtis, 1983).

Quanto aos dados referentes à temperatura de globo negro, os valores registrados para os diferentes sistemas de aquecimento estudados apresentaram o mesmo comportamento da Ts, em razão da pequena variação apresentada entre as respectivas variáveis ambientais.

A variação da umidade relativa do ar, no interior dos escamoteadores, apresentou diferenças significativas, principalmente no abrigo equipado com lâmpada de infravermelho, que além de promover altas temperaturas no interior do abrigo, reduziu significativamente a umidade relativa no seu interior, pois, o volume de ar se contrai e/ou expande com a variação da temperatura. Essa variação de volume impõe um limite à quantidade de vapor d'água que pode ser retida pelo volume de ar, ou seja, quanto maior a temperatura, maior a quantidade máxima saturante de vapor d'água. Dessa forma, verificam-se baixos valores de UR para essa situação.

Com relação ao tratamento com piso térmico, a energia térmica radiante proveniente do piso não foi suficiente para promover redução da UR, nos níveis verificados nos demais tratamentos, apresentando valor mais próximo do ideal, entre 60 e $70 \%$ (Nääs, 1989; Silva, 1999) (Figura 2).

As médias dos índices de temperatura de globo negro e umidade (ITGU), carga térmica radiante (CTR) e entalpia $(\mathrm{H})$, correspondentes ao período estudado (inverno), em função dos tratamentos adotados, estão apresentadas na Tabela 2 .

O índice de temperatura de globo negro e umidade (ITGU) apresentou valores médios para resistência elétrica, lâmpada incandescente e lâmpada de infravermelho, que não diferiram estatisticamente. $\mathrm{O}$ menor valor médio de ITGU foi verificado para o tratamento piso térmico, diferindo estatisticamente dos demais.

Com relação ao ITGU, considerando-se o dia de menor entalpia, na $1^{\mathrm{a}}, 2^{\mathrm{a}}$ e $3^{\mathrm{a}}$ semana avaliadas, verifica-se na Figura 3, que os abrigos equipados com lâmpada incandescente e resistência elétrica, foram aqueles que apresentaram valores mais próximos do ideal, 82 a 84 (Necoechea, 1986), para os três dias críticos. Os abrigos equipados com lâmpada de infravermelho e piso térmico apresentaram valores acima e abaixo do recomendado, respectivamente.
Tabela 2 - Valores do índice de conforto, umidade de globo preta (ITGU), carga de calor brilhante (CTR) e entalphy $(H)$, durante a estadia dos porquinho na casa de maternidade

Table 2 - Average values of the comfort index, black globe humidity (ITGU), radiant heat Load (CTR) and entalphy $(H)$, during the permanence of the piglets in the farrowing house

\begin{tabular}{|c|c|c|c|}
\hline $\begin{array}{l}\text { Tratamentos } \\
\text { Treatments }\end{array}$ & $\begin{array}{c}\text { ITGU } \\
\left(\mathrm{W} \cdot \mathrm{m}^{-2}\right)\end{array}$ & $\begin{array}{c}\mathrm{CTR} \\
\left(\mathrm{kJ} \cdot \mathrm{kg}^{-1}\right)\end{array}$ & $\mathrm{H}$ \\
\hline $\begin{array}{l}\text { Piso térmico } \\
\text { Heat mat }\end{array}$ & $77,5 b$ & $473,0 \mathrm{~d}$ & $68,9 d$ \\
\hline $\begin{array}{l}\text { Heat mat } \\
\text { Lâmpada incandescente } \\
\text { Standard heat lamp }\end{array}$ & $81,3 a$ & $493,2 \mathrm{c}$ & $72,1 \mathrm{c}$ \\
\hline $\begin{array}{l}\text { Resistência elétrica } \\
\text { Eletric resistence }\end{array}$ & $82,3 a$ & $496,5 b$ & $75,9 b$ \\
\hline $\begin{array}{l}\text { Lâmpada de infravermelho } \\
\text { Infrared lamp }\end{array}$ & $81,1 \mathrm{a}$ & $554,6 a$ & $81,1 \mathrm{a}$ \\
\hline
\end{tabular}

Valores médios com letras diferentes, na mesma coluna, diferem $(P<0,01)$ estatisticamente pelo teste Tukey.

Average values with differents letters, in the same column, differ $(P<.01)$ by Tukey test.

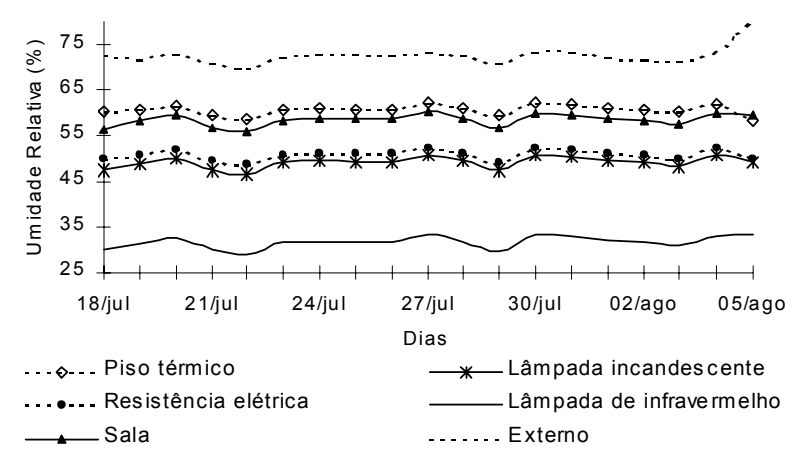

Figura 2 - Variação da umidade relativa média diária nos diferentes tratamentos na sala da maternidade e no abrigo meteorológico (ambiente externo).

Figure 2 - Variation daily average relative humidity in the different treatments in the farrowing house and the meterological shelter (external environment).

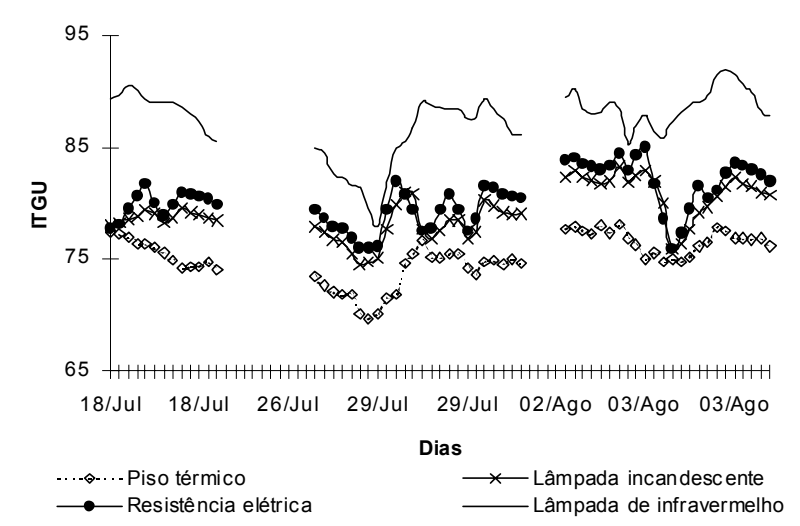

Figura 3 - Variação do índice de temperatura de globo negro e umidade para os dias de menor entalpia na etapa de inverno

Figure 3 - Variation of the black globe humidity index in lowest enthalpy days. 
Observando-se os valores médios da CTR, verificam-se diferenças significativas para lâmpada de infravermelho, resistência elétrica, lâmpada incandescente e piso térmico. O maior valor de CTR foi observado para o tratamento lâmpada de infravermelho, observando-se valores superiores à energia radiante média recomendada, de aproximadamente 450 W.m ${ }^{-2}$ (Baêta \& Souza, 1997). A CTR apresentada pelo piso térmico foi aquela que mais se aproximou da condição recomendada, $473 \mathrm{~W} \cdot \mathrm{m}^{-2}$. Além da fonte de aquecimento, atribui-se os altos valores de CTR no interior dos abrigos, por se tratar de um ambiente pequeno, vedado, com pequena velocidade de ar $\left(0,03 \mathrm{~m} \cdot \mathrm{s}^{-1}\right)$. Deve-se considerar que a CTR é influenciada pelo efeito convectivo juntamente com a temperatura média radiante. Pelos dados apresentados, nota-se que todos excederam a condição recomendada para os animais.

Comparando-se a CTR de cada tratamento, para os dias considerados críticos, verifica-se que o tratamento piso térmico foi aquele que apresentou valores mais próximos do recomendado, permitindo um fluxo de calor de aproximadamente $450 \mathrm{~W} . \mathrm{m}^{-2}$ (Baêta e Souza, 1997). Para os outro sistemas de aquecimento, todos apresentam valores superiores àquele considerado suficiente para manutenção da condição de conforto dos leitões (Figura 4).

Os valores médios da entalpia $(\mathrm{H})$ apresentaram diferenças estatísticas entre todos os tratamentos. $\mathrm{O}$

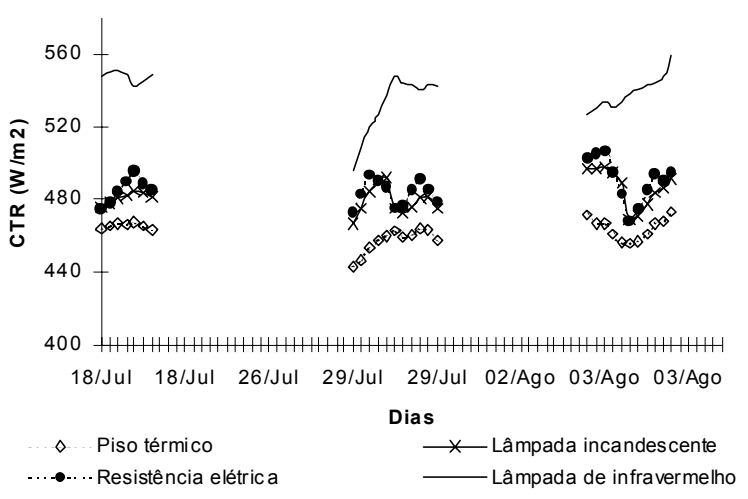

Figura 4 - Variação da carga térmica radiante (CTR), para os dias de menor entalpia, nos diferentes tratamentos avaliados.

Figure 4 - Variation of the radiant thermal load in lowest enthalpy days, for the different evaluated treatments. maior valor verificado foi para o abrigo equipado com lâmpada de infravermelho, seguido pelos abrigos com resistência elétrica, lâmpada incandescente e piso térmico, respectivamente, expressando a quantidade de energia interna da parcela de ar, nos microambientes avaliados, em relação à soma de suas componentes, de uma mistura de ar seco e vapor d'água, considerando-se a Ts $\left({ }^{\circ} \mathrm{C}\right)$ e a razão de mistura (kg de vapor d'água/kg de ar seco).

Pode-se verificar, na Figura 5, que a variação entálpica nos tratamentos adotados, para $1^{\mathrm{a}}$ semana experimental, não atingiu o valor ideal de $90,2 \mathrm{~kJ} / \mathrm{kg}$ ar seco, em nenhum dos tratamentos avaliados, sendo que o sistema de aquecimento, que mais se aproximou do valor recomendado, foi a lâmpada de infravermelho. Para a $2^{\mathrm{a}}$ semana, o tratamento mais eficiente foi a resistência elétrica, que apresentou valores mais próximos de $81,6 \mathrm{~kJ} / \mathrm{kg}$ ar seco. Na última semana, os tratamentos lâmpada incandescente e resistência elétrica foram aqueles que melhor se ajustaram à condição ideal, de $73,8 \mathrm{~kJ} / \mathrm{kg}$ ar seco, o piso térmico, esteve sempre abaixo da condição entálpica necessária ao conforto dos leitões.

As aproximações dos valores de entalpia, recomendada para os animais, foram calculadas com base nas condições de conforto dos animais, 32,30 e $28^{\circ} \mathrm{C}$, e umidade relativa de 70\%, citadas por Silva (1999), para a primeira, segunda e terceira semanas de vida dos leitões, respectivamente.

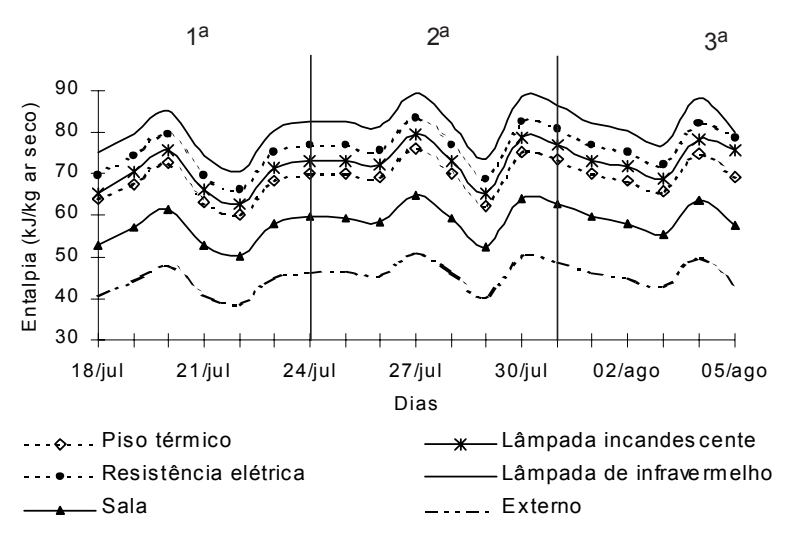

Figura 5 - Variação da entalpia média diária nos diferentes tratamentos na sala da maternidade e no abrigo meteorológico (ambiente externo).

Figure 5 - Variation of the daily average enthalpy in the different treatments in the farrowing house and the meteorological shelter (external environment). 
Tabela 3 - Equações de regressão ajustadas para porcentagem de animais no abrigo, em função da temperatura da sala da maternidade $\left({ }^{\circ} \mathrm{C}\right)$, correspondente à $3^{a}$ semana de vida dos animais, para os tratamentos adotados

Table 3 - Regression equations fitted for the \% of animals inside creeps, in function of the farrowing house temperature $\left({ }^{\circ} \mathrm{C}\right)$, correspondent to the $3^{\text {rd }}$ life week of the animals, for the studied treatments

\begin{tabular}{lcc}
\hline $\begin{array}{l}\text { Tratamentos } \\
\text { Treatments }\end{array}$ & $\begin{array}{c}\text { Equações ajustadas } \\
\text { Ajusted equations }\end{array}$ & $\mathrm{R}^{2}$ \\
\hline $\begin{array}{l}\text { Piso térmico } \\
\text { Heat mat }\end{array}$ & $\mathrm{y}=-0,1342 \mathrm{x}+3,5299 *$ & 0,9554 \\
$\begin{array}{l}\text { Lâmpada } \\
\text { incandescente }\end{array}$ & $\mathrm{y}=-0,1411 \mathrm{x}+3,5405 *$ & 0,9124 \\
$\begin{array}{l}\text { Standard heat lamp } \\
\text { Resistência } \\
\text { elétrica }\end{array}$ & $\mathrm{y}=-0,1043 \mathrm{x}+2,6624 *$ & 0,9055 \\
$\begin{array}{l}\text { Electric resistence } \\
\text { Lâmpada de } \\
\text { infravermelho } \\
\text { Infrared lamp }\end{array}$ & $\mathrm{y}=-0,1178 \mathrm{x}+3,0462 *$ & 0,9690 \\
\hline
\end{tabular}

*Significativo a $1 \%$ de probabilidade.

${ }^{*}$ Significantly at $1 \%$ of probability.
Deve-se considerar que, para análise da freqüência de acesso dos leitões ao abrigo escamoteador, foram analisados os três dias considerados críticos do período. Dessa forma, baseando-se no tempo de permanência dos animais dentro dos abrigos observados na Tabela 4, selecionou-se o dia 03/08/02 para análise individual, em intervalos de 1 hora, da freqüência de acesso.

De acordo com as Figuras 6 (a), (b), (c) e (d), verificou-se que a freqüência de acesso aos abrigos está diretamente relacionada com a variação de temperatura. Em todos os casos, observa-se que, quando houve redução da temperatura na sala da maternidade, mínima observada às $6 \mathrm{~h}$, verificou-se a maior freqüência de acesso aos abrigos.

Verifica-se que, no tratamento piso térmico, houve maior freqüência de acesso dos leitões ao longo do dia, praticamente em todos os horários, variando com a temperatura na sala (Figura 6 a).
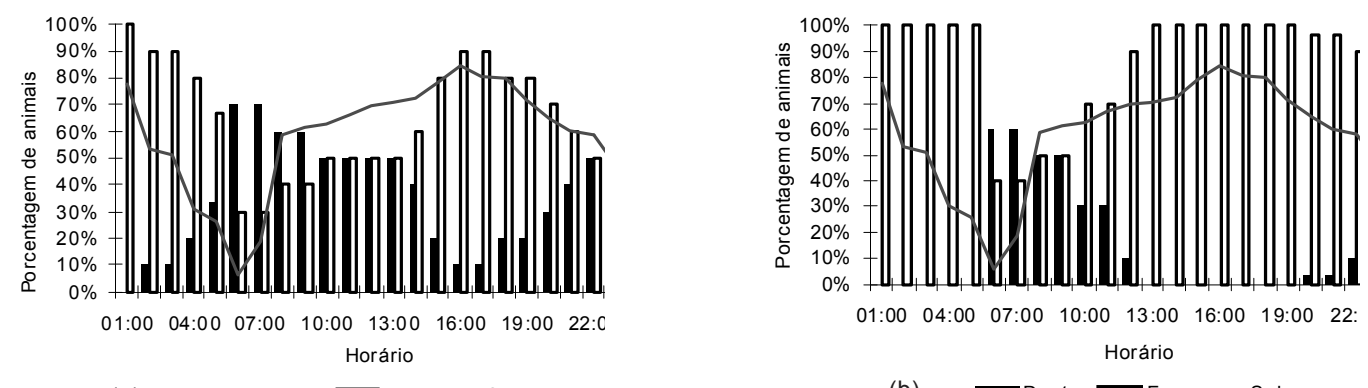

(a)

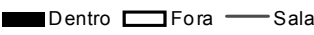

(b)

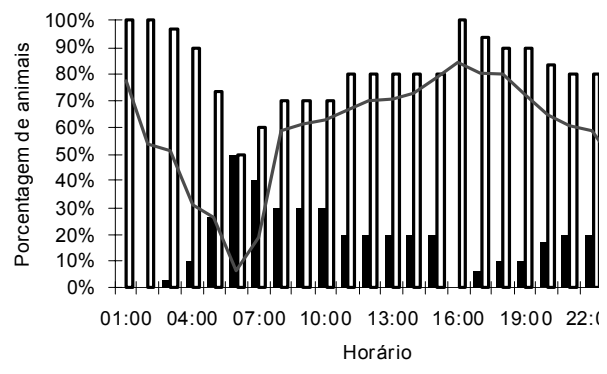

(c)

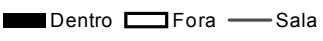

(d)

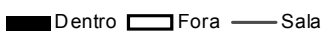

Figura 6 - Avaliação da freqüência de acesso ao abrigo escamoteador equipado com piso térmico (a), lâmpada incandescente (b); resistência elétrica (c); lâmpada de infravermelho (d) e a variação da temperatura na sala da maternidade, para o dia avaliado (03/08/02).

Figure 6 - Frequency of pig usage in creeps in relation with room temperatures, for the critical day, 08/03/2002. Being: a - heatedfloor, $b$ - standard lamps, $c$ - electrical resistance and $d$-infrared lamps. 
Tabela 4 - Porcentagem de permanência dos leitões no interior do abrigo escamoteador para os diferentes sistemas de aquecimento testados

Table 4 - Percentage of piglet permanence inside the creeps for the different tested heating systems

Porcentagem (\%) de permanência do tempo total

Percentage (\%) of permanence of total time

\begin{tabular}{|c|c|c|c|c|c|c|c|c|c|c|}
\hline \multirow[b]{2}{*}{$\begin{array}{l}\text { Dias } \\
\text { Days }\end{array}$} & \multirow[b]{2}{*}{$\begin{array}{l}\mathrm{Tm} \\
\left({ }^{\circ} \mathrm{C}\right)\end{array}$} & \multirow[b]{2}{*}{$\begin{array}{c}\mathrm{H} \\
(\mathrm{kJ} / \mathrm{kg})\end{array}$} & \multicolumn{2}{|c|}{$\begin{array}{l}\text { Piso térmico } \\
\text { Heated floor }\end{array}$} & \multicolumn{2}{|c|}{$\begin{array}{l}\text { Lâmpada incandescente } \\
\text { Standard lamp }\end{array}$} & \multicolumn{2}{|c|}{$\begin{array}{l}\text { Resistência elétrica } \\
\text { Electric resistence }\end{array}$} & \multicolumn{2}{|c|}{$\begin{array}{c}\text { Lâmpada de infravermelho } \\
\text { Infrared lam }\end{array}$} \\
\hline & & & $\begin{array}{l}\text { Dentro } \\
\quad I n\end{array}$ & $\begin{array}{c}\text { Fora } \\
\text { Out }\end{array}$ & $\begin{array}{l}\text { Dentro } \\
\text { In }\end{array}$ & $\begin{array}{c}\text { Fora } \\
\text { Out }\end{array}$ & $\begin{array}{l}\text { Dentro } \\
\text { In }\end{array}$ & $\begin{array}{c}\text { Fora } \\
\text { Out }\end{array}$ & $\begin{array}{l}\text { Dentro } \\
\text { In }\end{array}$ & $\begin{array}{c}\text { Fora } \\
\text { Out }\end{array}$ \\
\hline $18 / 07$ & 24,5 & 53,1 & 83 & 17 & 74 & 26 & 48 & 52 & 78 & 22 \\
\hline $29 / 07$ & 24,1 & 52,5 & 83 & 17 & 52 & 48 & 65 & 35 & 87 & 13 \\
\hline 03/08 & 25,8 & 55,3 & 100 & 0 & 43 & 57 & 96 & 4 & 87 & 13 \\
\hline \multicolumn{3}{|c|}{$\begin{array}{l}\text { Valores médios } \\
\text { Average values }\end{array}$} & 89 & 11 & 56 & 44 & 70 & 30 & 84 & 16 \\
\hline
\end{tabular}

A freqüência de acesso foi pontual, ou seja, das 5 às $11 \mathrm{~h}$, retomando a utilização das 19 às $23 \mathrm{~h}$, quando a temperatura voltou a reduzir (Figura 6 b).

Essa tendência pode ser verificada nos demais tratamentos, em que se pode observar que, para o dia crítico, a predominância de freqüência de acesso aos abrigos pelos leitões foi piso térmico, resistência elétrica, lâmpada de infravermelho e lâmpada incandescente, respectivamente.

As equações de regressão ajustadas para a porcentagem de animais no interior dos abrigos, em função da temperatura na sala da maternidade, para cada tratamento, correspondente à $3^{\mathrm{a}}$ semana experimental, são apresentadas na Tabela 3. A Tabela 3 está relacionada com o dia 03/08/02, considerado crítico do período e de maior freqüência de acesso, no decorrer de 24 horas.

Testando-se os modelos apresentados, nota-se que a redução da temperatura no interior da sala da maternidade, promove maior freqüência de acesso dos leitões ao abrigo, verificando-se que o tratamento piso térmico é aquele que melhor representa a condição térmica ambiental considerada mais adequada para os leitões. Para os demais tratamentos, lâmpada incandescente, resistência elétrica e lâmpada de infravermelho ambos apresentaram as mesmas respostas em relação ao comportamento dos leitões.

Com relação à análise do comportamento dos leitões, por meio do monitoramento, pelas microcâmeras e pela identificação eletrônica, verifica-se que a utilização dos sistemas de aquecimento foi influenciada pelas condições ambientais na sala da maternidade e no interior dos abrigos, que, na maioria dos casos, atendia a necessidade dos animais. O escamoteador equipado com piso térmico foi o mais visitado e aquele onde os leitões permaneceram por mais tempo (Tabela 4). Para a resistência elétrica e lâmpada de infravermelho, nota-se que o tempo de permanência dos animais no interior do abrigo foi alto, uma vez que o sistema de aquecimento atendia suficientemente às necessidades dos animais. Com relação à lâmpada incandescente, observa-se menor tempo de permanência dos animais no interior do abrigo, na $3^{\text {a }}$ semana avaliada, fato que pode estar relacionado à idade dos animais com menor exigência térmica.

Considerando-se que os sistemas de aquecimento permaneceram acionados durante toda fase de inverno, o piso térmico apresentou maior freqüência de uso e tempo de permanência dos animais no escamoteador, justificando as melhores condições de conforto aos animais, por se tratar de um fluxo de calor condutivo e, por conseguinte, ser mais eficientes às trocas de calor. Dessa forma, quando o animal deita no piso, ele ganha calor, até que o equilíbrio do processo seja atingido, de 30 a $32^{\circ} \mathrm{C}$, faixa de aquecimento do piso, já que o sistema de aquecimento em questão não condicionou o abrigo como um todo, e os sensores para o registro das temperaturas estavam instalados a uma altura de $0,55 \mathrm{~m}$ do piso.

Quando se analisa o piso térmico nos abrigos, verifica-se que há maior procura, pois, em $89 \%$ do tempo (24 horas), constatou-se a presença de pelo menos 1 leitão, no interior do abrigo (Figura 7 a).

O abrigo com lâmpada incandescente foi o que apresentou menor tempo de permanência dos animais no abrigo, apresentando valor da ordem de $56 \%$ do tempo total (24 horas), quando comparado com os demais (Figura 7 b). 


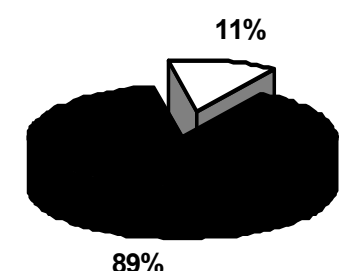

Dentro $\square$ Fora

(a)

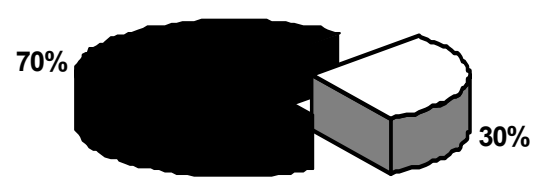

Dentro DFora

(c)

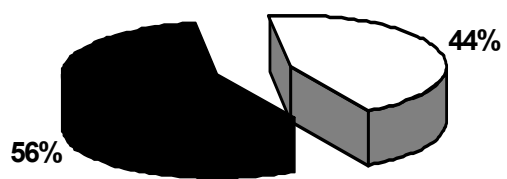

口entro $\square$ Fora

(b)

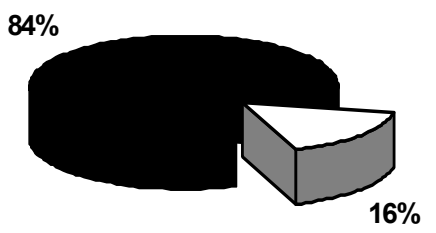

Dentro $\square$ Fora

(d)

Figura 7 - Porcentagem média do tempo de permanência dos leitões no abrigo escamoteador equipado com piso térmico (a), lâmpada incandescente (b), resistência elétrica (c) e lâmpada de infravermelho (d), durante às 24 horas de acionamento do sistema, para os dias críticos avaliados.

Figure 7 - Percentage time average permanence of the piglets in tested creep heated-floor (a), standard lamp (b), electric resistence (c), infrared lamp (d), critical days.

Com relação aos dados referentes ao abrigo equipado com resistência elétrica, observa-se que, cerca de $70 \%$ do tempo, verificou-se presença de leitões no interior do escamoteador, em virtude da própria condição ambiental proporcionada pela fonte de aquecimento, apresentando valores médios da ordem de $50,6 \%$ de UR, temperatura de $32,9^{\circ} \mathrm{C}$, entalpia de $76 \mathrm{~kJ} / \mathrm{kg}$ de ar seco, conforme os dados apresentados nas Tabelas 1 e 2, proporcionando condições mais próximas da faixa de conforto dos leitões (Figura $7 \mathrm{c}$ ).

No abrigo escamoteador com lâmpada de infravermelho, constatou-se permanência dos animais dentro do mesmo de $84 \%$ do tempo ( 24 horas), como se pode observar na Figura $7 \mathrm{~d}$, em função das condições ambientais proporcionadas pela fonte de aquecimento, apresentando valores médios da ordem de $31,7 \%$ de UR, $40,4^{\circ} \mathrm{C}$ de temperatura, entalpia de $81,1 \mathrm{~kJ} / \mathrm{kg}$ ar seco, conforme os dados apresentados nas Tabelas 1 e 2 .

Com relação ao ganho de peso dos leitões, observa-se que todos os tratamentos avaliados atingiram os índices desejados (Figura 8), ou seja, para todos os sistemas de aquecimento, os leitões atingiram ganho de peso diário de $0,240 \mathrm{~kg}$, para leitões nascidos com peso médio de $1,8 \mathrm{~kg}$ e desmame aos 18 dias com peso médio de 6,4 kg (Mores et al., 1998).

Não houve mortalidade entre os leitões que utilizaram os abrigos com os respectivos tratamentos estudados, apesar de a média registrada na sala da maternidade ser, aproximadamente, de $5 \%$, considerando-se dentro de um valor médio adequado, especialmente se relacionados com o alto número de leitões nascidos por parto (média 11,9). 


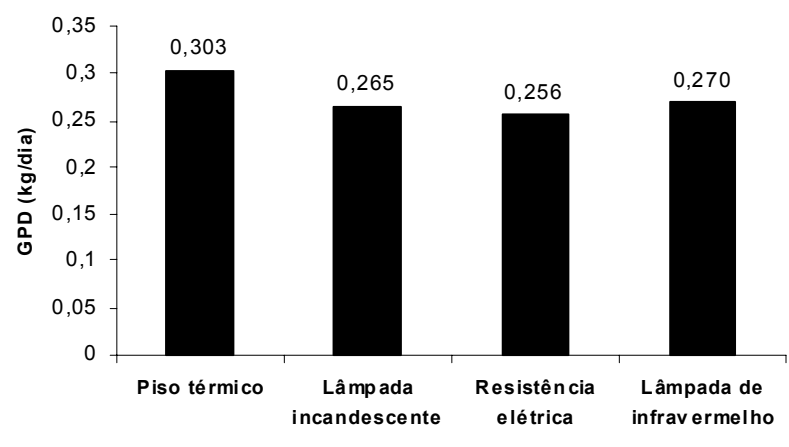

Figura 8 - Ganho de peso (kg/dia) dos leitões submetidos aos diferentes sistemas de aquecimento.

Figure 8 - Piglet daily weight gain (kg/day) for the different treatments.

\section{Conclusões}

Baseando-se nos resultados desta pesquisa, podese concluir que o uso de aquecimento para os leitões no período de inverno para a localidade estudada é indispensável, em virtude das baixas temperaturas registradas, sendo que os sistemas de aquecimento que se mostraram mais adequados, do ponto de vista térmico, foram lâmpada incandescente e resistência elétrica, para as duas semanas iniciais, entretanto, considerando o reflexo do aquecimento no comportamento dos leitões na terceira semana, o piso térmico foi o que proporcionou melhor condição de conforto aos animais, em função do maior tempo de permanência e freqüência de acesso ao escamoteador.

\section{Literatura Citada}

ALBRIGHT, L.D. Environment control for animals and plants. St. Joseph: American Society of Agricultural Engineers Michigan. 1990. p.453. (ASAE Textbook, 4)

BÄCKSTRÖM, L.; CURTIS, S.E. Housing and environmental influences on production. In: LEMAN, A.D. (Ed.) Diseases of swine. Ames: Iowa State University Press, 1981. p.737-753.

BAÊTA, F.C.; SOUZA, C.F. Ambiência em edificações rurais - conforto animal. Viçosa, MG: Universidade Federal de Viçosa, 1997. 246p.

BUFFINGTON, D.E.; COLAZZO-AROCHO, A.; CATON, G.H. Black globe humidity comfort index (BGHI) as comfort equation for dairy cows. Transaction of the ASAE, v.24, n.4, p.711-714, 1981 .
CURTIS, S.E. Environmental manegement in animal agriculture. Ames: State University Press, 1983. 409p.

ESMAY, M.L. Principles of animal environment. West Port CT: ABI, 1982. 325p.

MOUNT, L.E. The climate physiology of the pig. Baltimore: Williams and Welkins, 1968.271p.

MORES, N.; SOBESTIANSKY, J.; WENTZ, I. et al. Manejo do leitão do nascimento até o abate. In: SOBESTIANSKY, J.; WENTZ, I.; SILVEIRA, P.R.S. et al. (Eds.) Suinocultura intensiva. Concórdia: Embrapa Suínos e Aves, 1998.p.135-161.

MOURA, D.J.; NÄÄS, I.A.; SILVA, I.J.O. et al. The use entalpy as a thermal comfort index. In: LIVESTOCK EnVironment, 5., 1997, St. Joseph. Proceedings... St. Joseph: ASAE, 1997. v.1, p.242-248.

NÄÄS, I.A. Princípios de conforto térmico na produção animal. São Paulo: Ícone, 1989. 183p.

NECOECHEA, A.R. Doenças e meio ambiente. Suinocultura Industrial, v.8, n.8, p.13-26, 1986.

PERDOMO, C.C.; SOBESTIANSKY, J.; OLIVEIRA, P.V.A. et al. Efeito de diferentes sistemas de aquecimento no desempenho de leitões. Concórdia: Embrapa Suínos e Aves, 1987. p.1-3. (Comunicado Técnico, 122)

PEREIRA, A.R.; ANGELOCCI, L.R.; SENTELHAS, P.C. Agrometeorologia: fundamento e aplicações práticas. Guaíba: Agropecuária, 2002. 478p.

ROSSI, L.A.; CARDOSO, P.E.R.; BERALDO, A.L. Desempenho de placas de argamassa de cimento e casca de arroz aquecidas por resistência elétrica. In: CONGRESSO BRASILEIRO DE ENGENHARIA AGRÍCOLA, 31., 2002, Salvador. Anais. Salvador: Sociedade Brasileira de Engenharia Agrícola, 2002. p.249-252.

STATISTICAL ANALYSES SYSTEM - SAS. realease 6.08, (software). Cary: 1992. 620p.

SILVA, I.J.O. Qualidade do ambiente e instalações na produção industrial de suínos. In: SIMPÓSIO INTERNACIONAL DE SUINOCULTURA, São Paulo, 1999. Anais... São Paulo: Gessuli, 1999. p.108-325.

XIN, H.; SHAO, J. Real-time assessment of swine thermal comfort by computer vision. In: PROCEEDINGS OF THE WORLD CONGRESS OF COMPUTERS IN AGRICULTURE AND NATURAL RESOURCES, 2., 2002, Foz do Iguaçu. Proceedings... Foz do Iguaçu: American Society Agriculture Engineering, 2002. p.362-369.

Recebido em: 01/09/03

Aceito em: 13/10/04 